\title{
Research on the Socialist Political Economy with Chinese Characteristics in Facing the Challenges of the New Economic Era
}

\author{
Yating Zhang* \\ Xi'an Institute of Foreign Affairs, Xi'an 710000, Shaanxi Province, China \\ *Corresponding author: Yating Zhang, yatinazhang@163.com
}

\begin{abstract}
With the vigorous development of science and technology, emerging technologies such as big data, cloud computing, internet of things, and artificial intelligence have emerged. Driven by all these, the social economy in China is in the key stage of transformation into the new economic era. The international situation is also transforming, gradually changing from the economic system dominated by the traditional economy to the new economic system. Therefore, there is a need to conduct an in-depth analysis and research on the concept of "new economy"; that is, an economic form that integrates new technologies, industries, and models based on information technology or internet platforms. In combination of socialism with Chinese characteristics, it can be appreciated that with the arrival of the new economic era, there are great challenges to the productivity theory, labor value theory, and wealth theory under the traditional economic system. In order to effectively deal with the above challenges and adapt to the new economic development trend, there is a need to explore effective countermeasures from the perspective of the socialist political economy with Chinese characteristics in order to provide effective reference in predicting the trend of domestic economic development and docking with the new economic era.
\end{abstract}

Keywords: Socialism with Chinese characteristics; Political economy; New economy; Challenge

Publication date: June 2021; Online publication: June 30, 2021

\section{Introduction}

Under the background of social development in the new era, various emerging industries and economic subjects have emerged, which has changed the socio-economic form. In order to understand the socioeconomic law, the concept of "new economy" has been introduced. This concept which is an economic system dominated by information and scientific technology was put forward at the end of the 20th century. In 2014, the president clearly mentioned in his speech at the International Engineering Science and Technology Conference that the world economy is in a new economic development stage dominated by information technology. Therefore, the concept of "new economy" has attracted the attention of scholars, experts, and other societies. It has been regarded as a complex combination of informatization, digitization, intelligence, and sharing economy. Based on the momentum of the development of domestic economy along with flawless and matured technologies, such as the internet of things, big data, and artificial intelligence, relevant domestic personnel should explore effective measures to meet the challenges in combination with the economic principles and laws involved in political economics, place productivity in the first place, and actively develop the economy to optimize the superstructure in order to adapt to the development trend. In addition, facing the rapid rise of the new economy, people's lifestyles and thinking habits are deeply affected by it, thus giving birth to new productivity and industrial chains as well as changing the production relations. These bring challenges to the traditional socialist political economy with 
Chinese characteristics. Therefore, it is necessary to analyze and study it.

\section{Challenges to traditional political economics in the new economic era}

\subsection{Challenges to the wealth theory of traditional political economics}

First, a new form of data assets has been established, thus challenging the traditional asset theory. With the entrepreneurial development of new economy enterprises, a variety of new assets have emerged, such as data assets. Compared with the traditional forms, they have higher economic value in the new economic structure and the operation of enterprises. Second, the creation of new data wealth poses a challenge to the traditional financial theory. Many enterprises dominated by the internet business have rich data resources, and these data are assumed as new wealth under the new economic system. Through integration, analysis, and development, the above data can bring significant benefits to enterprises. For example, while providing consumers with functional services, such as retrieval, purchase, and feedback, JD or Taobao would also integrate consumers' preferences and purchase records in order to sort out available user data. In addition, more detailed information regarding consumers can be collected for payment, distribution, and other links. After secondary development, there is a possibility of bringing huge profits to enterprises. Third, a new form of welfare mechanism has been created, challenging the traditional welfare. The previous concept of welfare theory can be expressed as follows: the new economy is different from increasing additional benefits by increasing income or providing goods. Welfare distributions are often achieved by enjoying shared services. For example, Tencent has implemented the welfare mechanism by providing free or lowcost information resources or entertainment activities to customers so that the welfare level can be improved in the process of enjoyment.

\subsection{Challenges to the labor value theory of traditional political economics}

The challenges to the labor value theory are mainly in the form of labor subject. Born under the new economic background, creative labor is not only a basic form of labor, but also a value creation subject. In addition, under the concept of creative labor, it refers to intelligent forms of labor, such as research, innovation and discovery, scientific research and invention, technological innovation, software development, as well as product research and development. In a comprehensive view, the common feature is creativity. The labor factors based on the new economic model are also different from the past. They are generally comprised of network platforms, digital information, and intelligent machines. These are all highly innovative technologies, which can be combined and recursed based on modular characteristics. Many new technologies are developed on the basis of traditional technologies. Therefore, grouping technologies according to their functions can simplify the design steps, which is also the main factor for the modularization of technologies. In addition, through the combination and recursion of technologies, it is possible to correct the cognitive deviation of the essence of technology, and the combination and change of new technologies can be produced through creative labor. Generally speaking, creative labor has gradually become the primary demand of the new economy, and its value is largely determined by the degree of innovation and initiative of labor.

\subsection{Challenges to the productivity theory of traditional political economics}

When learning the theory of productivity under the new economic system, it is necessary to pay attention to the challenges brought by the functional improvement of advanced production factors to the traditional theory of production. Before that, it is important to first understand that the levels of production factors used in economic systems at different development stages varies and the key factors of productivity under the traditional economic model are capital and productivity whereas those under the new economic model 
are new contents, such as knowledge, technology, talents, information, data, and platforms. By comparing the above two, it can be appreciated that the research focus of traditional political economics is on material productivity, largely focusing on relatively simple production factors, such as labor objects and labor materials. The difference is that under the new economic model, production factors have entered the advanced stage, and the status of production factors have rose sharply. It is necessary to learn new supporting theories. In addition, in the process of understanding productivity, people gradually learn of the importance of innovation and understand that the core of the new economy lies in innovation, thus bringing challenges to the structure of the theory. Among them, economic development theory, an economic work, highlights the essence of innovation in economic development. Therefore, it is necessary to deeply explore the core connotation behind innovation, which does not only include the innovation and optimization of production technology as well as production mode, but also the gradual occupancy by entrepreneurs as the main position in the process of innovation and development; that is, to create a new production relationship, which can integrate production factors, regroup, and distribute data.

\section{Innovative measures of socialist political economy with Chinese characteristics to meet the challenges of the new economic era}

The establishment and development of political economy aims to elaborate and guide various abilities in real life. With the advent of the new economic era, it has brought new challenges to many fields. In order to actively respond to the above challenges, China should explore innovative measures and its development direction, perfect the modules of the political economy theory from the perspective of socialism with Chinese characteristics, and then provide theoretical support for practical activities.

The first measure is to enrich the financial theory and modernize it. Financial theory should be regarded as the fundamental of the political economy theory. Driven by the new economy, the form and matter of wealth have undergone positive qualitative changes from before. It can be seen from the combination of theory that financial theory is in the modern financial stage through multiple development stages, such as material, money, and ecology. Among them, the financial status of information, knowledge, and data is improving day by day. Therefore, it should also be expanded and supplemented on the basis of the original theory to bring finance in the form of information, knowledge, and data into the wealth system.

The second is to enrich the labor value theory and transform it into a quality type. It is understood that value theory is one of the basic theories of political economics. In order to conduct in-depth research, the scientific abstract method is generally adopted under the traditional model to remove the concept of poor quality. The traditional labor value theory tends to be quantitative, so the quality problem does not occur; however, the operation and development of economy are closely related to quantity. From the perspective of the new economy, value creation and distribution have changed, and the functions of high-end production factors, such as innovation, knowledge, and human capital, have been proposed. Therefore, it is necessary to improve and supplement the labor value theory system to ensure high-quality characteristics.

The third is to expand the content and scope of political economics. There are four elements as the foundation of the construction of basic theories in political economics, including the basic system, production, consumption, distribution, and so on. With the development and upgrading of the new economy, the basic content and scope are also changing and expanding; thus, it is essential to establish and expand new basic theories. Although the new economy has brought changes, it has not changed the essence of economic activities. It is related to production, exchange, distribution, and consumption, but the change of environment has brought new ways and improved operation efficiency. Therefore, in the changing environment, political economics should assume theoretical development as its foundation and core and carry out theoretical research on wealth, value, productivity, commodities, reproduction, as well as other related directions so as to further improve its practical interpretation ability. 
The fourth is to innovate research methods in time. Under the traditional concept of political economy, it is customary to judge the essential connotation of economic phenomena according to the scientific abstract method in order to highlight the scientificity of its methodology. With the advent of the new economy, the environment and form of economic activities have changed greatly. In the face of new phenomena and problems, political economics can find updated material content. First, it should be based on the scientific abstract method while integrating the case analysis method, empirical induction method, and historical statistics method to carry out research on new problems. This would aid in realizing the renewal and development of cases, concepts, categories, and theories. At the same time, it also improves the explanatory power of political economics under the new economic background and opens up a new path for development. Secondly, statistical methods and systems should be improved under the new economic background. On the one hand, a statistical index system that is suitable for the current environment should be formulated and the statistical investigation system should be further improved. On the other hand, new measurement methods should be proposed according to the new economic system to ensure that relevant statistical data would provide support and reference in the analysis, prediction, and early warning of the economic situation so as to truly promote the healthy development of China's new economy.

\section{Conclusion}

In order to adapt to the development trend of modernization and keep up with the upsurge of the new economic development, China should face the new challenges to the political and economic theory brought by the advent of the new economic era from the perspective of socialism with Chinese characteristics and actively explore innovative measures to deal with these challenges.

\section{Disclosure statement}

The author declares that there is no conflict of interest.

\section{References}

[1] Cheng H, Cheng Y, 2019, Research on the Logical Starting Point Category of Socialist Political Economy with Chinese Characteristics in the New Era. Contemporary Economic Research, (2): 34-41.

[2] Wang L, Chen X, 2018, On the Stages of the Development of Socialist Political Economy with Chinese Characteristics. Research on Mao Zedong and Deng Xiaoping Theory, (1): 50-56.

[3] Xiao B, Ai X, 2018, Xi Jinping's New Socialist Economic Thought with Chinese Characteristics to Lead the New Era of Economic Development - Summary of the Twenty-Eighth Annual Meeting of China China Economic Law Research Association. Contemporary Economic Research, 275(7): 93-98.

[4] Liu Y, Liu X, 2018, On the Innovation, Times and People of Socialist Political Economy with Chinese Characteristics. Journal of Weifang University. 